\title{
A bibliometric analysis of infectious diseases in patients with liver transplantation in the last decade
}

\author{
Han Zhong ${ }^{1,2 \#}$, Chun-Yan Liu ${ }^{3 \#}$, You-Qin Dai ${ }^{2 \#}$, Cheng Zhu ${ }^{4}$, Ke-Jia Le ${ }^{1}$, Xiao-Yun Pang ${ }^{1}$, Yu-Jie Li ${ }^{5}$, \\ Zhi-Chun Gu ${ }^{1}$, Yue-Tian Yu ${ }^{5}$
}

${ }^{1}$ Department of Pharmacy, Ren Ji Hospital, Shanghai Jiao Tong University School of Medicine, Shanghai, China; ${ }^{2}$ Department of Pharmacy, Ningbo Hangzhou Bay Hospital, Ningbo, China; ${ }^{3}$ Department of Emergency, Minhang District Central Hospital, Shanghai, China; ${ }^{4}$ Department of Disease Prevention and Control, Ruijin Hospital, Shanghai Jiao Tong University, School of Medicine, Shanghai, China; ${ }^{5}$ Department of Critical Care Medicine, Ren Ji Hospital, Shanghai Jiao Tong University School of Medicine, Shanghai, China

Contributions: (I) Conception and design: H Zhong, CY Liu; (II) Administrative support: YT Yu; (III) Provision of study materials or patients: ZC Gu, YT Yu, YJ Li; (IV) Collection and assembly of data: H Zhong, YT Yu; (V) Data analysis and interpretation: H Zhong, YT Yu, ZC Gu; (VI) Manuscript writing: All authors; (VII) Final approval of manuscript: All authors.

"These authors contributed equally to this work and should be considered as co-first authors.

Correspondence to: Yue-Tian Yu. Department of Critical Care Medicine, Ren Ji Hospital, Shanghai Jiao Tong University School of Medicine, Shanghai 200127, China. Email: fishyyt@sina.com; Zhi-Chun Gu. Department of Pharmacy, Ren Ji Hospital, Shanghai Jiao Tong University School of Medicine, 145 middle Shandong Road, Shanghai 200127, China. Email: guzhichun213@163.com.

Background: A bibliometric analysis was performed to reveal the current status of investigations in infectious diseases in patients with liver transplantation (LT) and to prioritize future research needs.

Methods: The present study comprehensively retrieved publications relevant to infectious diseases in LT recipients published between 2010 and 2020. The search was conducted on the Web of Science (WoS) database. A bibliometric analysis was conducted through machine learning and visualization tools, including VOSviewer, Bibliographic Item Co-Occurrence Matrix Builder, and Graphical Clustering Toolkit. Research hotspots and trends in the field were assessed, while the contributions and collaborations of countries, institutions, and authors were documented.

Results: A total of 691 publications were analyzed. Research output sharply increased in 2015, with a fast drop afterward. "Liver transplantation" was the most frequent keyword, with strong links to "hepatitis C virus" and "infection". Study areas included risk factors of infectious diseases in LT recipients, pathogens causing post-transplantation infections, antibacterial therapy and prophylaxis for peritransplant infection complications, living donor LT, and pediatric LT. The efficacy and safety of direct-acting antivirals (DAAs) for hepatitis $\mathrm{C}$ virus (HCV) infection among liver transplant recipients has attracted recent research interest. Didier Samuel was the most productive author, while Xavier Forns was the top-cited author. Shanghai Jiao Tong University was the most productive contributor, and Gilead Sciences was the most cited organization. Moreover, the USA was the greatest contributor. Gastroenterology was the most cited journal, while Liver Transplantation was the most prolific journal.

Conclusions: This bibliometric analysis will better understand the research status of infectious complications in LT recipients and forecast future research trends. Priority should be given to identifying risk factors for peritransplantation infections and effective treatments against infectious complications in the coming years.

Keywords: Infectious disease; liver transplantation (LT); bibliometric analysis; hotspots; trends

Submitted May 10, 2021. Accepted for publication Sep 22, 2021.

doi: $10.21037 / \mathrm{atm}-21-2388$

View this article at: https://dx.doi.org/10.21037/atm-21-2388 


\section{Introduction}

Liver transplantation (LT) has become a suggested therapy for patients with end-stage liver disease or fulminant liver failure (1,2). Between 2005 and 2015, there were 93,812 new waitlist registrants for LT in the USA (3). The most common etiologies for LT were alcoholic liver disease (ALD), nonalcoholic steatohepatitis (NASH), and hepatitis C virus (HCV) (4-6). For pediatric patients, the leading cause of LT was biliary atresia (7). Posttransplantation infections often occur after LT, with an incidence ranging from $5 \%$ to $48 \%$ due to the application of immunosuppressants and glucocorticoids $(8,9)$. Infectious complications are significant sources of prolonged length of mechanical ventilation (MV) and intensive care unit (ICU) stay, as well as early and long-term death for LT recipients $(8,10)$. Recipient age, pretransplant total psoas area (TPA), pretransplant total bilirubin level, Child-Pugh classification $\mathrm{C}$, and red blood cell transfusion were once identified as independent risk factors for postoperative infections $(10,11)$.

Bibliometric analysis has become a good tool for the quantitative analysis of academic research at diversified levels (12) and has been extensively used in various disciplines to examine scientific emphases and landmarks comprehensively $(13,14)$.

Therefore, we sought to conduct a bibliometric overview of relevant publications in the field of infectious diseases in patients with LT. Our overarching goals were to explore the significance of publications in this discipline and discover the research progress and hotspots.

\section{Methods}

\section{Search strategy}

The Web of Science (WoS) database (core collection database) (Thomson Reuters, New York, NY, USA), associated with the EmBase database, was chosen to conduct a comprehensive search from Jan $1^{\text {st }}, 2010$ to Dec $31^{\text {st }}$, 2020. The search strategy syntax included the following infection-related terms: "infectious disease", "infection", "pneumonia", "surgical site infection", "bloodstream infection", "abdominal infection", "urinary tract infection", "sepsis" based on infections with high incidence after LT $(8,9)$, and the LT-related terms were: "liver transplantation", "liver grafting", "liver transplant", "hepatic transplantation" according to the Medical Subject Headings (MeSH) database (https://www.ncbi.nlm.nih.gov/mesh/). The publication type was limited to original articles, while languages other than English were excluded.

\section{Bibliometric statistical analysis}

\section{Overview of WoS database output}

General characteristics of the retrieved documents were determined from each database, including the publication year, region or country, research category, authorship, and citation counts. The annual/national distribution and growth trends were visualized through the dycharts analysis platform (https://dycharts.com/).

\section{Network analysis}

The full data of the included publications were downloaded in text format from the WoS database. The bibliometric analysis was conducted through VOSviewer (version 1.6.10, Leiden University, Netherlands) to present the collaboration network, emphases, and future trends in the relevant field. The collected data were imported into VOSviewer software. Authorship, affiliation, citation, keywords, and theme words were extracted and analyzed. Finally, bubble maps were generated to visualize the bibliometric analysis results. In the bubble maps, colors indicate item clusters, and the distance and width of lines between two bubbles indicate the frequency of co-occurrence. The sizes of bubbles indicate the amounts of documents, citations, and occurrences in co-authorship, citations, keywords/theme words, co-occurrence analysis, respectively.

\section{Co-word analysis}

Co-word biclustering analysis can display hotspots in a research discipline. Bibliographic Item Co-Occurrence Matrix Builder (BICOMB) (version 2.0), created by Professor Lei Cui from China Medical University, extracted data from retrieved documents. Subsequently, high-frequency keywords/source documents and highfrequency keywords/high-frequency keywords matrices were generated. Then, the matrix was further analyzed and visualized by Graphical Clustering Toolkit (gCLUTO) software (Version 1.0) designed by Rasmussen and Karypis (University of Minnesota, Minneapolis, MN, USA). A heatmap matrix was then generated, in which the content of the column was the identification number of source literature, and the row was the high-frequency keyword. Therefore, the semantic relationships between highfrequency keywords and documents on infectious diseases in patients with LT were shown to reveal hotspots and their application domains. Meanwhile, the co-word clusters of 


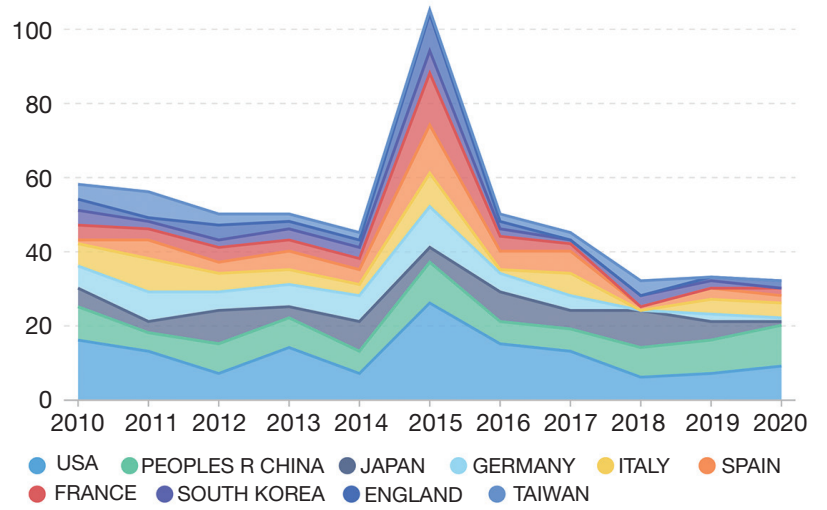

Figure 1 Overview of publication output. The annual amounts of publications of the top 10 prolific region/countries in infectious diseases in patients with liver transplantation researches from 2010 to 2020 .

high-frequency keywords were visualized by a mountain matrix.

\section{Results}

\section{Scientific performance and output}

A total of 619 documents on infectious diseases in patients with LT were identified in the WoS core database between January 2010 and December 2020. The literature counts by region/country were ranked to present the worldwide distribution of scientific literature in the field of infectious diseases in patients with LT (Figure 1). The USA [133], China [87], Japan [61], Germany [55], and Italy [51] were the most productive countries in terms of research on infectious diseases in patients with LT. The National Institutes of Health (NIH), USA [23], United States Department of Health Human Services [23], National Natural Science Foundation of China (NSFC) [16], Ministry of Education Culture Sports Science and Technology Japan (MEXT) [12], and NIH National Institute of Diabetes Digestive Kidney Diseases (NIDDK) [12] were the top five funding agencies. Transplantation [318], surgery [296], gastroenterology hepatology [287], immunology [145], and infectious diseases [127] were the most focused research areas. The volume of journals that published more than five manuscripts on infectious diseases in patients with LT was low [20], while 106 journals published relevant papers. Liver Transplantation [76], Transplantation [73], Hepatology [48], American Fournal of Transplantation [42], and Transplantation Proceedings [39] ranked as the top five source journals covering study areas of infectious diseases in patients with LT. Didier Samuel [25], Xavier Forns [19], Stefano Fagiuoli [17], Sarah Arterburn [15], and John G. Mchutchison [15] were the most productive authors. Shanghai Jiao Tong University [19], Sun Yat-Sen University [16], Hannover Medical School [15], University of Paris [15], and Hôpital Paul Brousse [14] stood out with the largest volume of output.

\section{Structural and thematic development}

There were 490 author keywords retrieved from the 619 included publications. Of these, 20 keywords were enrolled in the bibliographic analysis, as they appeared more than five times. "Liver transplantation" had the largest volume of occurrences [138] with a total link strength of 118 , and had strong links to "hepatitis C virus" (link strength, 25; occurrences, 32), "infection" (link strength, 11; occurrences, 15), "hepatitis C" (link strength, 10; occurrences, 12), and "hepatitis B virus" (link strength, 9; occurrences, 11) (Figure 2).

A total of 184 theme terms that appeared more than 10 times were retrieved. Then, they were divided into 6 theme clusters. The red cluster represented the risk factors, incidence, and mortality of infectious diseases after LT, and the green cluster represented antiviral therapy for the recurrence of HCV infection after LT. The blue cluster represented studies on preventing or prophylaxis of hepatitis B virus (HBV) recurrence after LT (Figure $3 A$ ). Figure $3 B$ shows the overlay visualization map of the theme terms. The color of the bubble presented the average time of publication. The yellow color indicated a recent hot topic. "DAA" was the newest study hotspot (occurrences, 11; average publication time, 2017), and "independent risk factor" (occurrences, 26; average publication time, 2016) was a current focus. Simultaneously, high-frequency theme words were also visualized by a word cloud. "Treatment", "hepatitis C virus infection", "donor liver transplantation", "risk factor", and "hepatitis C virus" were ranked as the top 5 active theme words (Figure S1).

\section{Bibliometric analysis of citations}

Table 1 shows the top 10 most cited documents in terms of infectious diseases in patients with LT. Most publications were trials investigating direct-acting antivirals (DAAs) for prophylaxis or treatment of HCV infection after LT. Simultaneously, epidemiological investigation also generated interest, including those on the prevalence of 


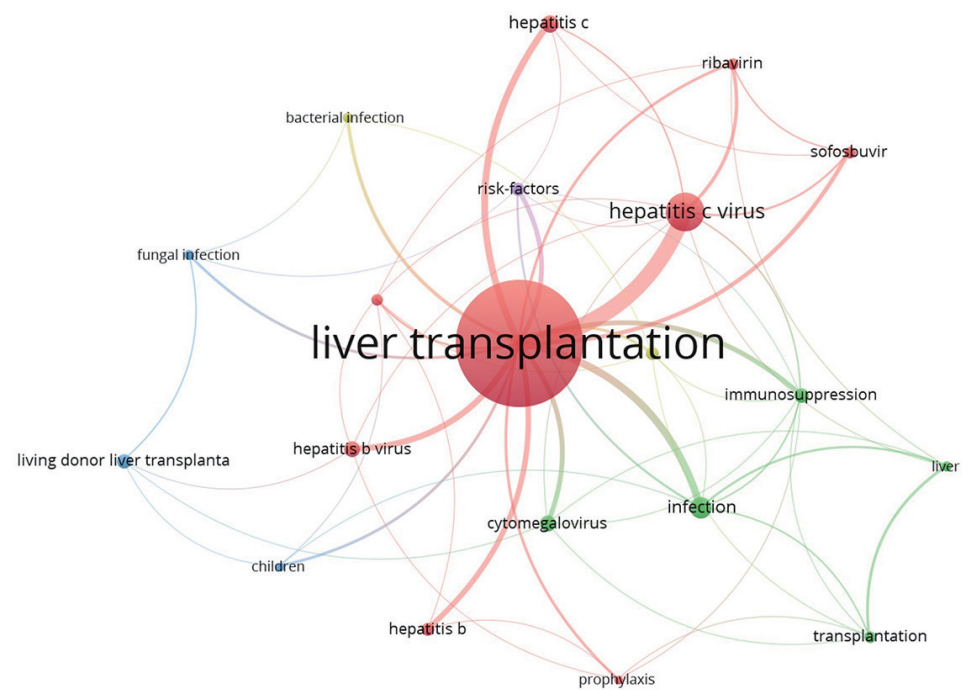

Figure 2 Bibliometric network of keywords. VOSviewer was used to analyse and visualize the co-occurrence of retrieved high-frequency author keywords. Various colors presented different clusters, bubble size revealed volume of appearances, the thickness of lines showed occurrence frequency of linkage.

A

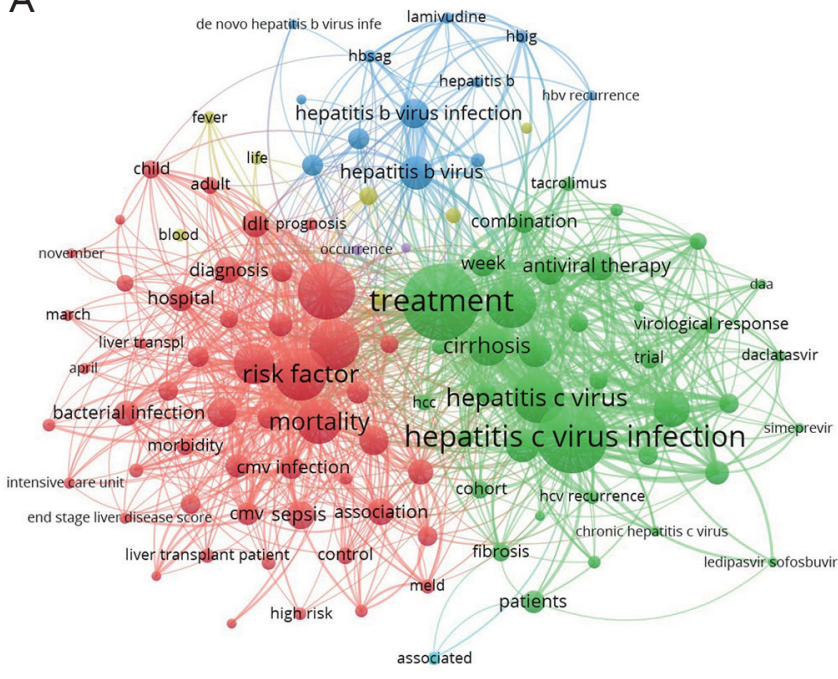

B

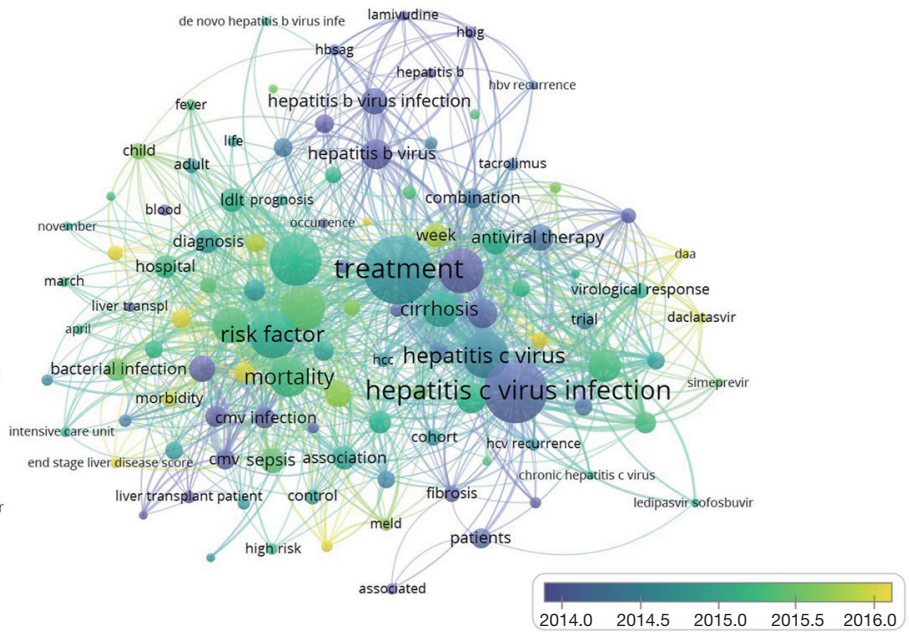

Figure 3 Bibliometric network of terms from title and abstracts. (A) Bubble network map of the theme terms; (B) bubble overlay map of the research topics. The bubble size represented the appearances of theme terms (A,B). The distance between bubbles exhibited their occurrence frequency. In map A, colors were used to distinguish terms clusters, while in map B, colors indicated average publication time.

HCV infection or ALD among liver transplant waitlist patients, polymorphisms of genotypes predicting antiviral therapy response in liver transplant recipients, and risk factors for infection in post-liver transplant patients. Moreover, hepatitis E infection in patients with LT was a hot topic. The article "Daclatasvir with sofosbuvir and ribavirin for $\mathrm{HCV}$ infection with advanced cirrhosis or post-liver transplantation recurrence", written by Poordad et al. and published in Hepatology in 2016, had the largest volume of citations [289]. The rankings of the top 10 mostcited authors, source journals, institutions, and countries are presented in Tables S1-S4. Xavier Forns from Hospital 
Table 1 The articles ranking top ten in volume of citations on infectious diseases in patients with liver transplantation

\begin{tabular}{|c|c|c|c|c|}
\hline Rank & Author (publication year) & Title & Journal & Citations \\
\hline 2 & Charlton M, et al. (2015) & $\begin{array}{l}\text { Sofosbuvir and Ribavirin for Treatment of Compensated Recurrent } \\
\text { Hepatitis C Virus Infection After Liver Transplantation }\end{array}$ & Gastroenterology & 257 \\
\hline 4 & Goldberg D, et al. (2017) & $\begin{array}{l}\text { Changes in the Prevalence of Hepatitis C Virus Infection, } \\
\text { Nonalcoholic Steatohepatitis, and Alcoholic Liver Disease Among } \\
\text { Patients with Cirrhosis or Liver Failure on the Waitlist for Liver } \\
\text { Transplantation }\end{array}$ & Gastroenterology & 236 \\
\hline 6 & Kamar N, et al. (2010) & $\begin{array}{l}\text { Pegylated Interferon-alpha for Treating Chronic Hepatitis E Virus } \\
\text { Infection after Liver Transplantation }\end{array}$ & $\begin{array}{l}\text { Clinical Infectious } \\
\text { Diseases }\end{array}$ & 126 \\
\hline 7 & Krell RW, et al. (2013) & $\begin{array}{l}\text { Association Between Sarcopenia and the Risk of Serious Infection } \\
\text { Among Adults Undergoing Liver Transplantation }\end{array}$ & Liver Transplantation & 124 \\
\hline 8 & Benson AB, et al. (2011) & $\begin{array}{l}\text { Differential Effects of Plasma and Red Blood Cell Transfusions on } \\
\text { Acute Lung Injury and Infection Risk Following Liver Transplantation }\end{array}$ & Liver Transplantation & 78 \\
\hline 9 & Halac U, et al. (2012) & Chronic hepatitis E infection in children with liver transplantation & Gut & 74 \\
\hline 10 & Cholankeril G, et al. (2018) & $\begin{array}{l}\text { Alcoholic Liver Disease Replaces Hepatitis C Virus Infection as the } \\
\text { Leading Indication for Liver Transplantation in the United States }\end{array}$ & $\begin{array}{l}\text { Clinical Gastroenterology } \\
\text { and Hepatology }\end{array}$ & 69 \\
\hline
\end{tabular}

Clinic Barcelona, who published 19 articles, was the most cited author (662 citations). Gastroenterology (impact factor 17.373 in 2019), which published 20 articles on infectious diseases in patients with LT, was the most cited journal (780 citations). An organization analysis revealed that Gilead Sciences (a pharmaceutical company), which published 10 articles, had the highest citations (608 citations). Moreover, the USA had the highest volume of citations $(2,210$ citations).

\section{Research botspots}

Biclustering analysis presented the matrix and mountain visualization of hot topics. A total of 19 high-frequency terms were retrieved (Table S5). Then, the word/source matrix and co-word matrices were generated, as shown in Table S6 and Table S7. In the visualization matrix, there were 3 clusters in the high-frequency keyword/source article matrix shown in the heatmap (Figure 4), while the high-frequency keyword co-word matrix is shown in the mountain diagram in Figure S2. These clusters were further analyzed to identify the narrower topics of each research group.
* Cluster 0: common infections pathogens after LT, including HBV, HCV, and human immunodeficiency virus;
* Cluster 1: risk factors for infection, including bacterial infection and cytomegalovirus infection, after living donor LT;
* Cluster 2: infections in pediatric patients with LT.

\section{Discussion}

In the present bibliometric analysis of infectious diseases in patients with LT, 691 publications were retrieved from the WoS core database. A comprehensive overview of research productivity regarding infectious diseases in patients with LT over the past decade was presented. Research output sharply increased in 2015 with a fast drop afterward, and the USA, Shanghai Jiao Tong University, and Didier Samuel were the greatest contributors at the national, organizational, and individual levels in this field. 


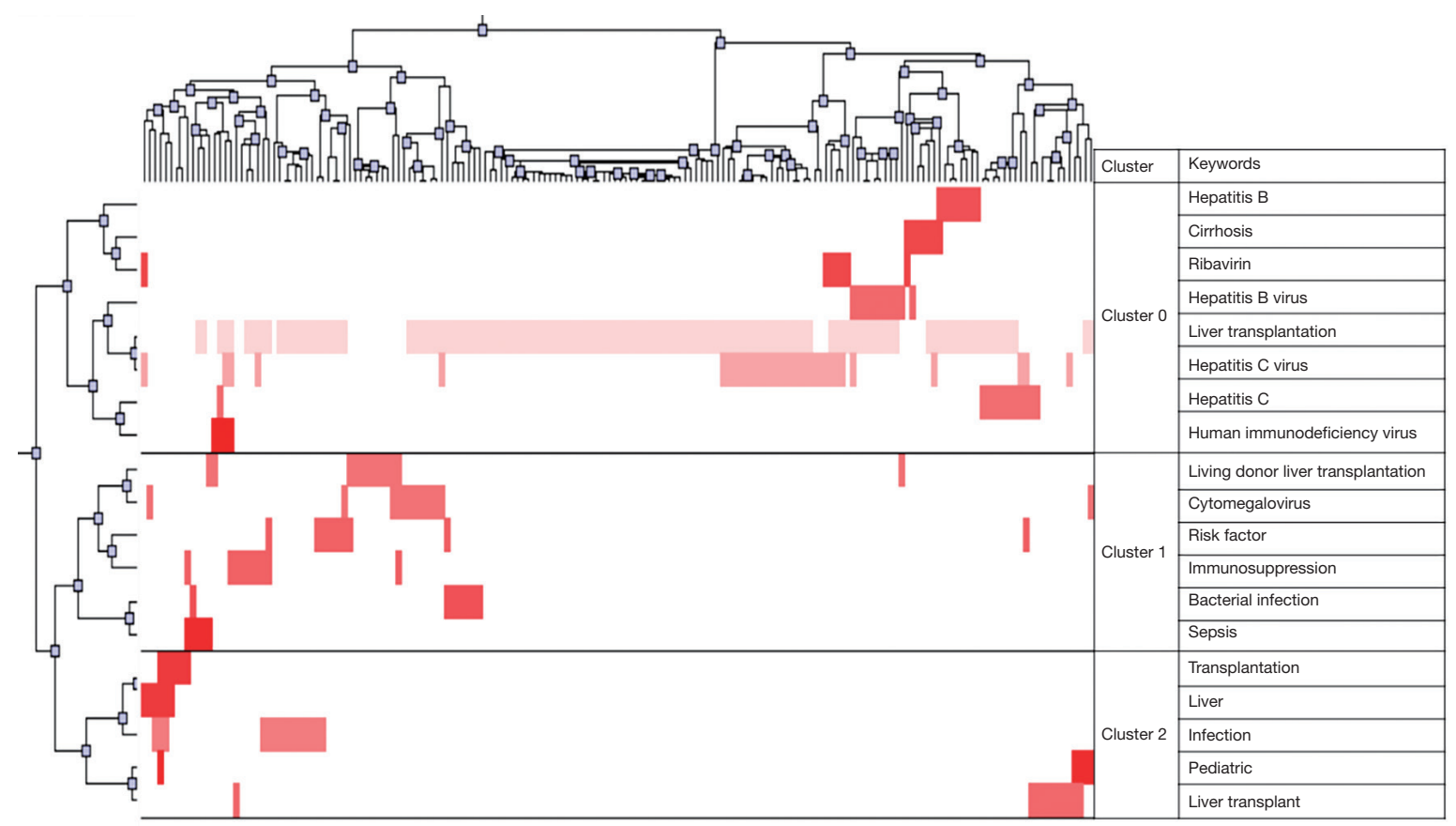

Figure 4 Visualization heatmap of highly frequent keywords/source literatures matrix in field of infectious diseases in patients with liver transplantation research. Block colors represented the frequency of appearance of keywords in documents. The color was darker if the keyword had higher frequency.

"Liver transplantation" was the most frequent keyword, with strong links to "hepatitis C virus" and "infection". Investigation areas included risk factors and the prevalence of infectious diseases in LT recipients, the most common pathogens causing post-transplantation infections, therapy, and prophylaxis for peritransplant infection complications, living donor LT, and pediatric LT. The efficacy and safety of DAAs for HCV infection among liver transplant recipients have attracted recent research interest.

LT has already developed into a guideline-recommended treatment for patients with terminal-stage liver diseases in the last decade $(15,16)$, and has achieved significant progress with improvements in surgical techniques. Since the early stage of this century, the survival rate after transplantation has been a success, far beyond $85 \%$ in the first year and close to $75 \%$ in the following 5 years (17). Moreover, with second-generation DAA agents' official recognition and approval, the survival rates may rise further (4). Thus, more operations were performed from 2015 to 2020 in China, the USA, and England in patients with hepatocirrhosis, biliary atresia, or even liver cancer. More studies were performed during that period, and more research papers were published that focused mainly on operative approaches, clinical effects, and opportunistic infections after transplantation $(18,19)$.

Published research has revealed that infectious diseases are the most common cause of death for LT patients (6). Viral hepatitis was once recognized as one of the most serious complications in the pre-and post-LT periods $(15,20)$. Hepatitis B immunoglobulin following LT has been widely used and recently replaced with nucleos $(\mathrm{t})$ ide analogs, which can notably inhibit viral reproduction (21). The guidelines recommend the paradigm change in the medication choices for chronic hepatitis $\mathrm{C}$, consisting of effective DAA therapies that almost universally have a curative effect $(22,23)$.

With the advancement of in vitro life support technology, more LT recipients are admitted to the ICU to successfully get through the perioperative period. Thus, hospitalacquired infections (HAIs) have attracted more attention in recent years (24). Bacterial infections account for approximately $36 \%$ of all secondary infectious diseases, followed by fungal infection (12\%) and cytomegalovirus infection (11\%) (25). It was suggested that the rational use of antimicrobial agents is the most significant factor, and hosts with high-risk factors should be carefully screened. Hence, more studies focused on prediction model establishment have been performed, and some nomograms 
have also been built $(26,27)$. Developing a reasonable course of antibiotics and exploring the interaction between the inflammatory response and host immune status are still future trends in this research area $(28,29)$.

The prophylactic use of antimicrobial agents is another challenge for LT recipients due to the immunosuppressive status. Reducing unnecessary antibiotic use and shortening treatment are still the cornerstones of antimicrobial stewardship. Molecular diagnosis methods including metagenomics next generation sequencing ( $\mathrm{mNGS}$ ) or $\mathrm{X}$-pert for pathogen detection have been developed rapidly in recent years, which may provide crucial support for the "precise treatment" of infectious diseases in LT recipients (30).

In this bibliometric analysis, publications on infections in LT patients in the last decade were fully screened and analyzed objectively and comprehensively. However, there were some limitations. First, the WoS core database only collected some of the newly added research papers that are updated daily in WoS. In addition, emerging operations on pediatric patients with congenital biliary atresia have been performed in China. Therefore, research published in Chinese might be vital and helpful. Nevertheless, as a limitation of VOSviewer, most articles published in languages other than English were excluded. Second, our study did not include some new studies published in preprint online databases, including MedRxiv.

This bibliometric analysis will better understand the research status of infectious complications in LT recipients and forecast future research trends. Priority should be given to identifying risk factors for peritransplantation infections and effective treatments against infectious complications in the coming years.

\section{Acknowledgments}

Funding: This study was funded by China International Medical Foundation (Z-2018-35-2003), WU JIEPING Medical Foundation (320.6750.2020-385 04-31), Research Funds of Shanghai Health and Family Planning commission (20184Y0022, 20194Y0007), Shanghai "Rising Stars of Medical Talents" Youth Development ProgramYouth Medical Talents: Clinical Pharmacist Program [SHWSRS(2021)_099], Chinese Society of Toxicology (GST2019CT308), Cultivation fund of clinical research of Renji Hospital (PY2018-III-06), and Clinical Pharmacy Innovation Research Institute of Shanghai Jiao Tong University School of Medicine (CXYJY2019ZD001, CXYJY2019QN004).

\section{Footnote}

Data Sharing Statement: Available at https://dx.doi. org/10.21037/atm-21-2388

Conflicts of Interest: All authors have completed the ICMJE uniform disclosure form (available at https://dx.doi. org/10.21037/atm-21-2388). The authors have no conflicts of interest to declare.

Ethical Statement: The authors are accountable for all aspects of the work in ensuring that questions related to the accuracy or integrity of any part of the work are appropriately investigated and resolved.

Open Access Statement: This is an Open Access article distributed in accordance with the Creative Commons Attribution-NonCommercial-NoDerivs 4.0 International License (CC BY-NC-ND 4.0), which permits the noncommercial replication and distribution of the article with the strict proviso that no changes or edits are made and the original work is properly cited (including links to both the formal publication through the relevant DOI and the license). See: https://creativecommons.org/licenses/by-nc-nd/4.0/.

\section{References}

1. Cornberg M, Buti M, Eberhardt CS, et al. EASL position paper on the use of COVID-19 vaccines in patients with chronic liver diseases, hepatobiliary cancer and liver transplant recipients. J Hepatol 2021;74:944-51.

2. Vibert E, Duclos-Vallée JC, Ghigna MR, et al. Liver transplantation for hepatocellular carcinoma: the impact of human immunodeficiency virus infection. Hepatology 2011;53:475-82.

3. Tanaka S, Fujita K, Kanaoka M, et al. Prospective study of objective physical activity and quality of life in living donor liver transplant recipients. Jpn J Nurs Sci 2020;17:e12362.

4. Cholankeril G, Ahmed A. Alcoholic Liver Disease Replaces Hepatitis C Virus Infection as the Leading Indication for Liver Transplantation in the United States. Clin Gastroenterol Hepatol 2018;16:1356-8.

5. Noureddin M, Vipani A, Bresee C, et al. NASH Leading Cause of Liver Transplant in Women: Updated Analysis of Indications For Liver Transplant and Ethnic and Gender Variances. Am J Gastroenterol 2018;113:1649-59.

6. Goldberg D, Ditah IC, Saeian K, et al. Changes in the Prevalence of Hepatitis C Virus Infection, Nonalcoholic 
Steatohepatitis, and Alcoholic Liver Disease Among Patients With Cirrhosis or Liver Failure on the Waitlist for Liver Transplantation. Gastroenterology 2017;152:1090-1099.e1.

7. Nikeghbalian S, Malekhosseini SA, Kazemi K, et al. The Largest Single Center Report on Pediatric Liver Transplantation: Experiences and Lessons Learned. Ann Surg 2021;273:e70-2.

8. Weiss E, Dahmani S, Bert F, et al. Early-onset pneumonia after liver transplantation: microbiological findings and therapeutic consequences. Liver Transpl 2010;16:1178-85.

9. Benson AB, Burton JR Jr, Austin GL, et al. Differential effects of plasma and red blood cell transfusions on acute lung injury and infection risk following liver transplantation. Liver Transpl 2011;17:149-58.

10. Krell RW, Kaul DR, Martin AR, et al. Association between sarcopenia and the risk of serious infection among adults undergoing liver transplantation. Liver Transpl 2013;19:1396-402.

11. Kaido T, Mori A, Ogura Y, et al. Pre- and perioperative factors affecting infection after living donor liver transplantation. Nutrition 2012;28:1104-8.

12. Yu Y, Li Y, Zhang Z, et al. A bibliometric analysis using VOSviewer of publications on COVID-19. Ann Transl Med 2020;8:816.

13. Ahmad P, Asif JA, Alam MK, et al. A bibliometric analysis of Periodontology 2000. Periodontol 2000 2020;82:286-97.

14. Zyoud SH, Smale S, Waring WS, et al. Global research trends in microbiome-gut-brain axis during 2009-2018: a bibliometric and visualized study. BMC Gastroenterol 2019;19:158.

15. Te H, Doucette K. Viral hepatitis: Guidelines by the American Society of Transplantation Infectious Disease Community of Practice. Clin Transplant 2019;33:e13514.

16. Green M, Blumberg EA, Danziger-Isakov L, et al. Foreword: 4th edition of the American Society of Transplantation Infectious Diseases Guidelines. Clin Transplant 2019;33:e13642.

17. Roberts MS, Angus DC, Bryce CL, et al. Survival after liver transplantation in the United States: a diseasespecific analysis of the UNOS database. Liver Transpl 2004;10:886-97.

18. Bajaj JS. Alcohol, liver disease and the gut microbiota. Nat Rev Gastroenterol Hepatol 2019;16:235-46.

19. Milosevic I, Vujovic A, Barac A, et al. Gut-Liver Axis, Gut Microbiota, and Its Modulation in the Management of Liver Diseases: A Review of the Literature. Int J Mol Sci 2019;20:395.

20. Mohammed A, Paranji N, Chen PH, et al. COVID-19 in Chronic Liver Disease and Liver Transplantation: A
Clinical Review. J Clin Gastroenterol 2021;55:187-94.

21. Wu L, Xu W, Li X, et al. The NTCP p.Ser267Phe Variant Is Associated With a Faster Anti-HBV Effect on FirstLine Nucleos(t)ide Analog Treatment. Front Pharmacol 2021;12:616858.

22. Bradshaw D, Mbisa JL, Geretti AM, et al. Consensus recommendations for resistance testing in the management of chronic hepatitis $\mathrm{C}$ virus infection: Public Health England HCV Resistance Group. J Infect 2019;79:503-12.

23. Colombo MG, Musabaev EI, Ismailov UY, et al. Consensus on management of hepatitis $\mathrm{C}$ virus infection in resourcelimited Ukraine and Commonwealth of Independent States regions. World J Gastroenterol 2019;25:3897-919.

24. Sakpal SV, Donahue S, Crespo HS, et al. Utility of fiber-optic bronchoscopy in pulmonary infections among abdominal solid-organ transplant patients: A comprehensive review. Respir Med 2019;146:81-6.

25. Ferrarese A, Zanetto A, Becchetti C, et al. Management of bacterial infection in the liver transplant candidate. World J Hepatol 2018;10:222-30.

26. Yu Y, Shen H, Zhu C, et al. Infections Caused by Extended-Spectrum $\beta$-Lactamase Producing Escherichia Coli in Systemic Lupus Erythematosus Patients: Prevalence, Risk Factors, and Predictive Model. Biomed Res Int 2018;2018:8296720.

27. Li Y, Shen H, Zhu C, et al. Carbapenem-Resistant Klebsiella pneumoniae Infections among ICU Admission Patients in Central China: Prevalence and Prediction Model. Biomed Res Int 2019;2019:9767313.

28. Yu Y, Li J, Wang S, et al. Effect of Candida albicans bronchial colonization on hospital-acquired bacterial pneumonia in patients with systemic lupus erythematosus. Ann Transl Med 2019;7:673.

29. Shen H, Yu Y, Chen SM, et al. Dectin-1 Facilitates IL-18 Production for the Generation of Protective Antibodies Against Candida albicans. Front Microbiol 2020;11:1648.

30. Brink AJ, Richards G. Best practice: antibiotic decisionmaking in ICUs. Curr Opin Crit Care 2020;26:478-88.

(English Language Editors: C. Betlazar-Maseh and J. Chapnick)

Cite this article as: Zhong H, Liu CY, Dai YQ, Zhu C, Le KJ, Pang XY, Li YJ, Gu ZC, Yu YT. A bibliometric analysis of infectious diseases in patients with liver transplantation in the last decade. Ann Transl Med 2021;9(22):1646. doi: 10.21037/ atm-21-2388 


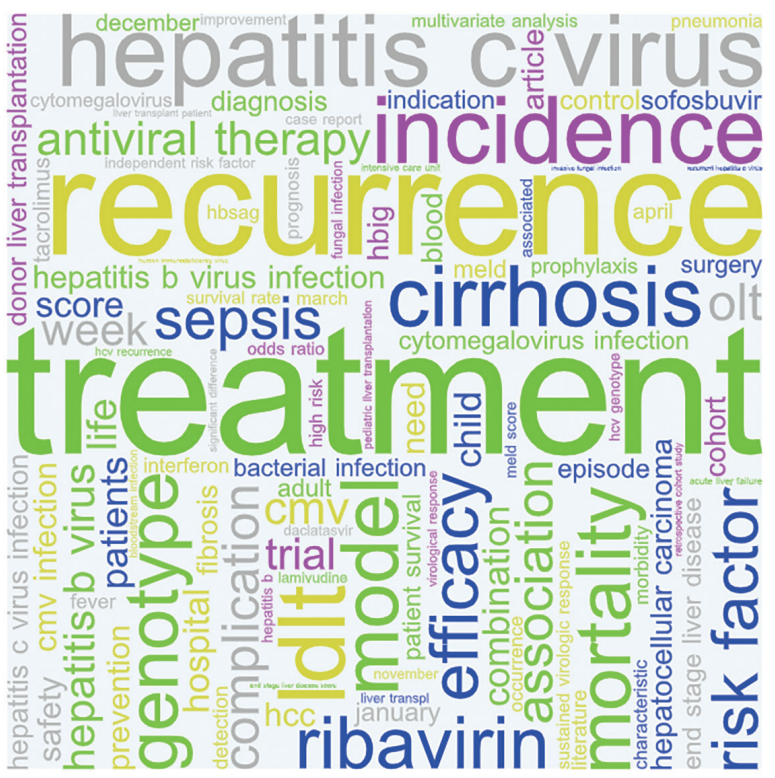

Figure S1 Word cloud of the occurrence rates of high-frequency theme words.

Table S1 The top ten most cited authors in the field of infectious diseases in patients with liver transplantation

\begin{tabular}{|c|c|c|c|c|}
\hline Author & Documents & Citations & Organizations & Countries \\
\hline John G. Mchutchison & 12 & 577 & Gilead Sciences & USA \\
\hline Sarah Arterburn & 12 & 576 & Gilead Sciences & USA \\
\hline Michael P. Curry & 6 & 571 & Beth Israel Deaconess Medical Center & USA \\
\hline Jill Denning & 9 & 504 & Gilead Sciences & USA \\
\hline Edward Gane & 9 & 504 & Auckland City Hospital & New Zealand \\
\hline Michael Charlton & 5 & 496 & Mayo Clinic & USA \\
\hline Didier Samuel & 25 & 484 & Hôpital Paul Brousse, Centre Hépatobiliaire, and Université Paris Sud & France \\
\hline
\end{tabular}


Table S2 The top ten most cited source journals in the field of infectious diseases in patients with liver transplantation

\begin{tabular}{lcc}
\hline Source & Documents & Citations \\
\hline Gastroenterology & 20 & 780 \\
Hepatology & 48 & 660 \\
Liver Transplantation & 76 & 601 \\
Transplant Infectious Disease & 21 & 209 \\
Transplantation Proceedings & 39 & 202 \\
Journal of Hepatology & 35 & 191 \\
Transplantation & 73 & 121 \\
American Journal of Transplantation & 42 & 119 \\
World Journal of Gastroenterology & 15 & 119 \\
Gut & 5 & 75 \\
\hline
\end{tabular}

Table S3 The top ten most cited institutions in the field of infectious diseases in patients with liver transplantation

\begin{tabular}{lccc}
\hline Organization & Documents & Citations & Country \\
\hline Gilead Sciences & 10 & 608 & USA \\
Beth Israel Deaconess Medical Center & 10 & 597 & USA \\
University of California, San Francisco & 10 & 595 & USA \\
University of Miami & 5 & 583 & USA \\
University of Michigan & 5 & 581 & USA \\
Auckland City Hospital & 7 & 580 & New Zealand \\
Columbia University & 7 & 493 & USA \\
Mayo Clinic & 11 & 463 & USA \\
Duke University & 5 & 403 & France \\
Hôpital Paul Brousse & 14 & 4 & \\
\hline
\end{tabular}


Table S4 The top ten most cited countries in the field of infectious diseases in patients with liver transplantation

\begin{tabular}{lcc}
\hline Country & Documents & Citations \\
\hline USA & 133 & 2210 \\
Spain & 48 & 821 \\
France & 38 & 747 \\
New Zealand & 15 & 639 \\
Germany & 55 & 586 \\
Japan & 61 & 336 \\
Peoples Republic of China & 84 & 320 \\
Netherlands & 20 & 271 \\
Italy & 51 & 254 \\
England & 27 & 155 \\
\hline
\end{tabular}

Table S5 Highly frequent major keywords from the included publications in the field of infectious diseases in patients with liver transplantation

\begin{tabular}{|c|c|c|}
\hline Rank & Keywords & Occurrence \\
\hline 1 & Liver transplantation & 131 \\
\hline 2 & Hepatitis $\mathrm{C}$ virus & 33 \\
\hline 3 & Infection & 15 \\
\hline 4 & Living donor liver transplantation & 13 \\
\hline 6 & Hepatitis C & 12 \\
\hline 7 & Hepatitis B virus & 11 \\
\hline 8 & Liver transplant & 11 \\
\hline 9 & Risk factors & 10 \\
\hline 13 & Ribavirin & 7 \\
\hline 14 & Cirrhosis & 7 \\
\hline 15 & Liver & 6 \\
\hline 16 & Transplantation & 6 \\
\hline 17 & Sepsis & 5 \\
\hline 18 & Human immunodeficiency virus & 5 \\
\hline 19 & Pediatric & 5 \\
\hline
\end{tabular}


Table S6 Highly frequent keyword/source article matrix

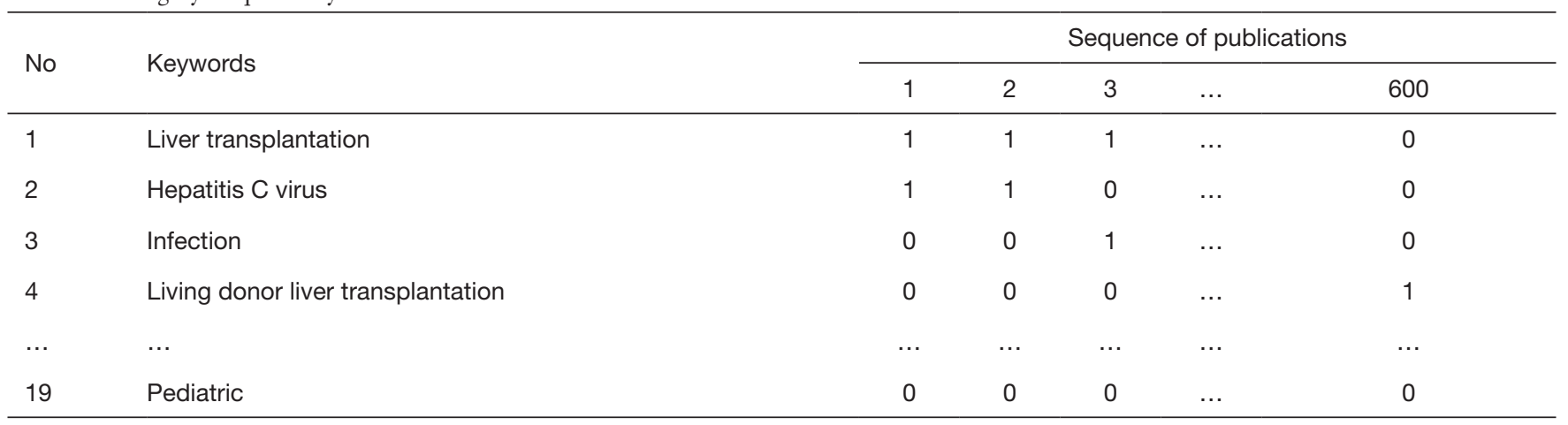

Table S7 Co-word matrix of high-frequency keyword

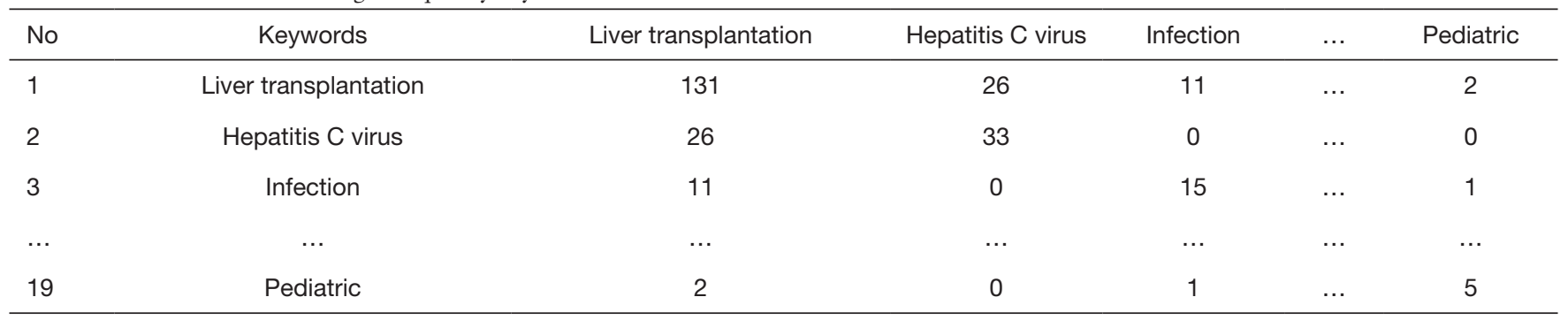

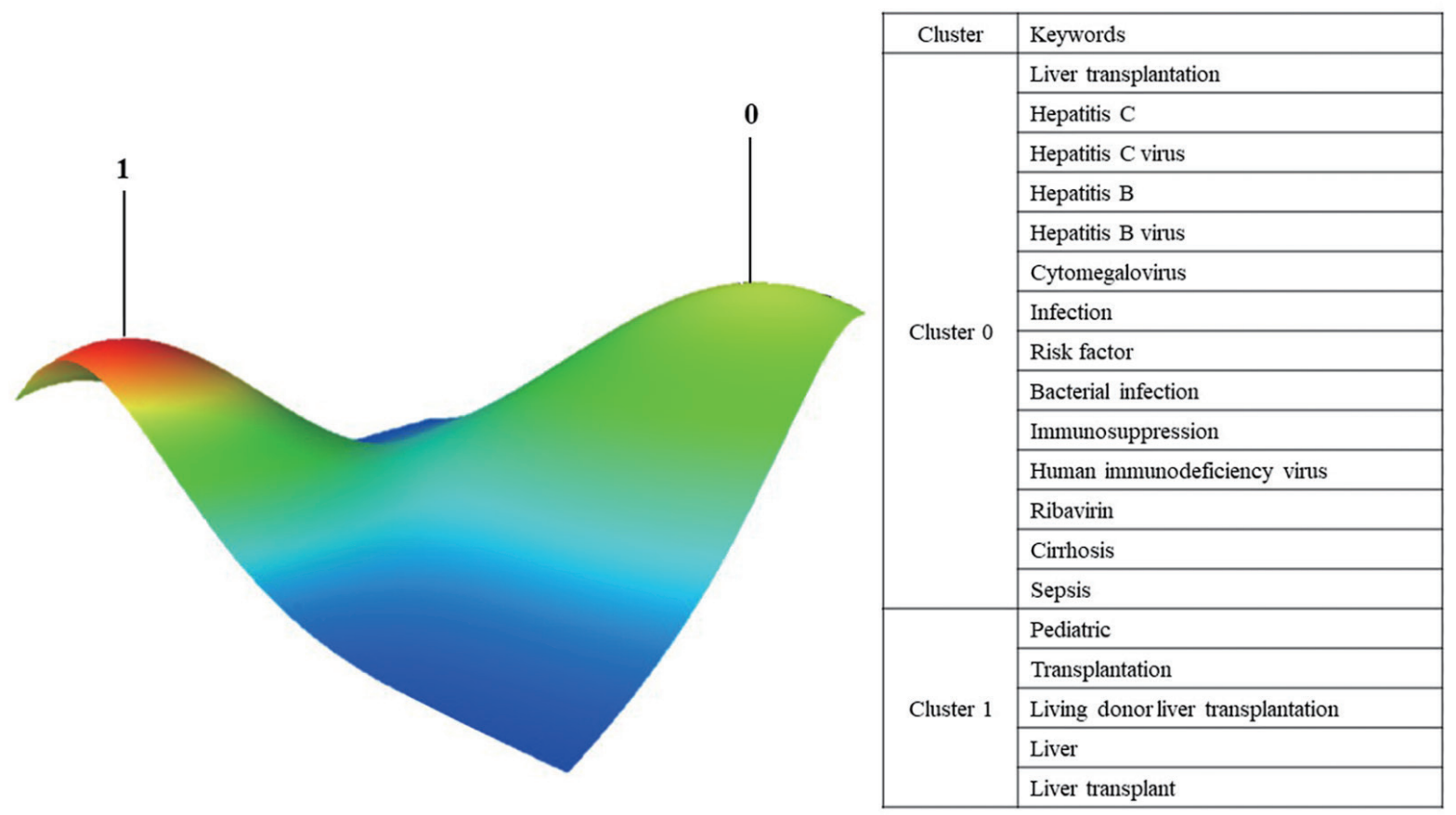

Figure S2 Mountain visualization map of high-frequency keywords and documents in field of infectious diseases in patients with liver transplantation research. 